\title{
Does Mercury Vapor Exposure Increase Urinary Selenium Excretion?
}

Key words : Elemental mercury-Mercury vapor exposure-Selenium-Urinary Excretion-Workers

Urinary selenium concentrations are known to be greater in workers exposed to elemental mercury vapor (hereafter refered to as mercury vapor) than in non-exposed control subjects, ${ }^{1)}$ and a worker exposed to mercury vapor was found to have an elevated urinary selenium level. ${ }^{2}$ ) These two reports suggest that an increase of urinary selenium excretion may occur as a result of mercury vapor exposure. However, experimental data regarding the interaction between mercury vapor and selenium have yielded ambiguous results about the retention and elimination of selenium due to mercury vapor exposure, ${ }^{3,4)}$ and the decrease of selenium excretion due to mercury in the form of mercuric mercury $\left(\mathrm{Hg}^{2+}\right) .^{5,6)}$

In this study, we measured urinary mercury and selenium in workers with or without exposure to mercury vapor to determine whether or not urinary selenium excretion was increased as a result of mercury vapor exposure. Urine samples were collected from 141 workers, 71 men and 70 women, whose extent of exposure to mercury vapor varied according to their job sites. These samples of singly voided urine were stored in a freezer until analyzed.

Selenium was measured by the following procedure: To $1 \mathrm{~m} l$ of urine, $2 \mathrm{~m} l$ of conc. $\mathrm{HNO}_{3}$ were added and heated at $120^{\circ} \mathrm{C}$ for $3 \mathrm{~h}$ using a Teflon-lined, high pressure decomposition vessel (Uniseal Decomposition Vessels, Ltd.). One $\mathrm{m} l$ of this digested solution was heated with $0.5 \mathrm{ml}$ of conc. $\mathrm{HClO}_{4}$ at $190^{\circ} \mathrm{C}$ for $1.5 \mathrm{~h}$ to eliminate $\mathrm{HNO}_{3}$, and then selenium was determined by a fluorometric method using 2,3-diaminonaphthalene. ${ }^{7)}$ The sensitivity of this method was $1 \mathrm{ng}$. Total mercury was measured by the Magos method (sensitivity $1 \mathrm{ng}$ ). ${ }^{8)}$ Creatinine was measured by spectrometry using Jaffe's reaction. Levels of selenium and mercury in urine were expressed as $\mathrm{nmol} / \mathrm{mmol}$ creatinine, and converted to logarithms for statistical analysis.

Workers were divided into five groups according to their urinary mercury levels (Table 1). The mercury level in group I was less than $2.8 \mathrm{nmol} / \mathrm{mmol}$ creatinine which means that this group was mostly free from mercury exposure. The average age was almost identical among the groups.

For both sexes, group V (with the highest urinary mercury level) had the lowest urinary selenium level, but one-way variance analysis (ANOVA) did not reveal any significant variations of urinary selenium with urinary mercury levels; however a weak, but significant, negative correlation between mercury and selenium was found in men. When both sexes were combined (the total in the table), variations of urinary selenium reached significance with a significantly lower 
Table 1. Urinary selenium concentrations (USe) of workers according to their urinary mercury levels

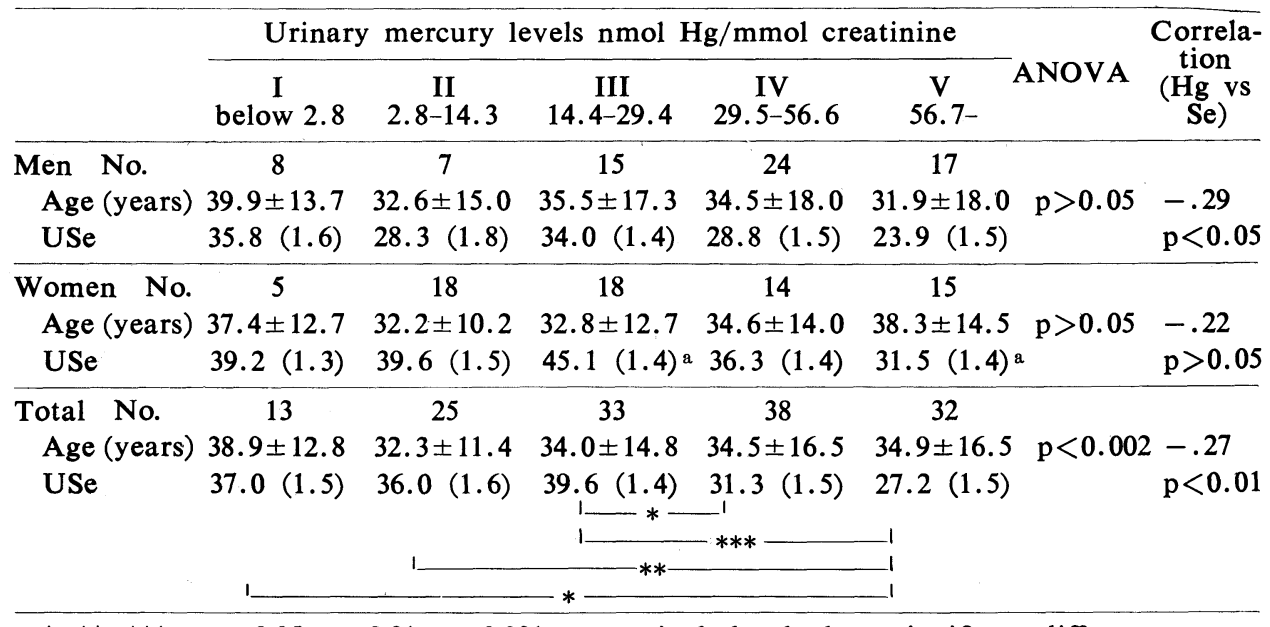

$*, * *, * * *: \mathrm{p}<0.05, \mathrm{p}<0.01, \mathrm{p}<0.001$, respectively by the least significant difference test.

Age: Arithmetic mean \pm standard deviation. a : Significant $(\mathrm{p}<0.05)$ difference between sexes.

USe: Urinary selenium concentration expressed as $\mathrm{nmol} \mathrm{Se} / \mathrm{mmol}$ creatinine, and the values in the table are geometric means with their deviations in parentheses.

level in group V compared to groups I, II and III by the least significant difference test ${ }^{9)}$ and also a lower level in group IV compared to group III.

The present results are not consistent with those of the previous reports. ${ }^{1,2)}$ Our results may indicate that mercury vapor exposure does not necessarily increase urinary selenium excretion in general but rather decreases it at higher exposure levels. In the report by Alexander et al., ${ }^{1)}$ which dealt with male workers only, the average urinary selenium level was $39 \mathrm{nmol} / \mathrm{mmol}$ creatinine in unexposed controls while the average urinary mercury level of exposed workers was 30.7 (range: $2.2-111$ ) $\mathrm{nmol} / \mathrm{mmol}$ creatinine, both being almost identical to the present results. Therefore, the variation of urinary selenium excretion occurring as a result of mercury vapor exposure can not be explained by the level of mercury exposure from these contradictory results obtained in the present study and that of Alexander et al.

On the other hand, urinary selenium levels have been known to reflect dietary selenium intake. ${ }^{10)}$ The variance of urinary selenium excretion in mercury workers may be a coincidental phenomenon with variable dietary selenium intake by workers. To ascertain the effect of mercury vapor exposure on selenium metabolism, we therefore need to perform further studies. 


\section{REFERENCES}

1) Alexander, J., Thomassen, Y. and Aaseth, J. (1983). Increased urinary excretion of selenium among workers exposed to elemental mercury vapor, J. Appl. Toxicol., 3, 143.

2) Hojo, Y. (1981). Subject groups high and low in urinary selenium levels: workers exposed to heavy metals and patients with cancer and epilepsy, Bull. Environm. Contam. Toxicol., 26, 466.

$3)$ Nygaard, S.-P. and Hansen, J. C. (1978). Mercury-selenium interaction at concentrations of selenium and of mercury vapours as prevalent in nature, Bull. Environm. Contam. Toxicol., 20, 20.

4) Hansen, J. C., Kristensen, P. and Westergaard, I. (1981). The influence of selenium on mercury distribution in mice after exposure to low dose $\mathrm{Hg}^{0}$ vapours, J. Appl. Toxicol., $1,149$.

5) Magos, L. and Webb, M. (1976). Differences in distribution and excretion of selenium and cadmium or mercury after their simultaneous administration subcutaneously in equimolar doses, Arch. Toxicol., 36, 63.

6) Kristensen, P. and Hansen, J. C. (1980). Urinary and fecal excretion of selenium $\left(\mathrm{Na}_{2}{ }^{75} \mathrm{SeO}_{3}\right)$ and mercury $\left({ }^{203} \mathrm{HgCl}_{2}\right)$ administered separately and simultaneously to mice, Toxicology, 16, 39.

7) Watkinson, J. H. (1966). Fluorometric determination of selenium in biological material with 2,3-diaminonaphthalene. Anal. Chem., 38, 92.

8) Magos, L. (1971). Selective atomic-absorption determination of inorganic mercury and methylmercury in undigested biological samples, Analyst, 96, 847.

9) Snedecor, G. W. and Cochran, W. G. (1967). Statistical Methods, 6th edition, The Iowa State University Press, Ames.

10) Levander, O. A., Sutherland, B., Morris, V. C. and King, J. C. (1981). Selenium metabolism in human nutrition. In:Selenium in Biology and Medicine (Edited by Spallholz, J. E., Martin, J. L. and Ganther, H. E.), pp. 256-268, AVI Publishing Company, Inc., Westport, Connecticut.

Department of Human Ecology,

School of Health Sciences,

Faculty of Medicine,

University of Tokyo,

3-1, Hongo 7-chome, Bunkyo-ku,

Tokyo 113, Japan

Department of Hygiene,

Fukushima Medical College,

75, Sugitsuma-machi 5-chome, Fukushima-shi,

Fukushima 960, Japan

Kantoh-Rosai Hospital

2035, Kizukisumiyoshi-machi, Nakahara-ku,

Kawasaki-shi, Kanagawa 211, Japan

\author{
Tetsuro HONGO \\ Tsuguyoshi SUZUKI \\ Seiichiro HIMENO \\ and Chiho WATANABE
}

Hiroshi SATOH

Yukihiko SHIMADA

(Received November 30, 1984 and in revised form January 21, 1985) 